\title{
Educational Intervention Program for Coping with Youth Cyberbullying, Based on Bystanders'
}

\section{Involvement}

\author{
Dorit Olenik-Shemesh ${ }^{1, *}$, Tali Heiman ${ }^{1} \&$ Yael Zur ${ }^{1}$ \\ ${ }^{1}$ Education and Psychology Department, The Open University of Israel, Israel \\ *Corresponding author: Education and Psychology Department, The Open University of \\ Israel, 1 University Road, Raanana, Israel. Tel: 972-544-508-787. E-mail: \\ doritol@openu.ac.il
}

Received: March 25, 2019 Accepted: April 21, 2019 Published: June 24, 2019

doi:10.5296/ije.v11i2.14999 URL: https://doi.org/10.5296/ije.v11i2.14999

\begin{abstract}
The current article presents an intervention program for coping with cyberbullying, focused on the role of bystanders, as well as evaluation of the program's effectiveness. While most intervention programs for coping with cyberbullying focus on deterring cyber-perpetrators or assisting cyber-victims, the program presented in this study focuses on the role of bystanders in coping with cyberbullying, providing assistance to victims and strengthening their circle of support. Based on the results of a previous study, a unique intervention program was developed, implemented, and evaluated. The program consisted of six instructional experiential meetings addressing the following topics: noticing the cyberbullying event, interpreting it as an emergency, identifying and emphasizing the abuse, taking responsibility for the event, gaining knowledge and discussing effective ways to intervene and report and more. The homeroom teachers presented the intervention program after receiving training. 418 adolescents participated, divided into experimental $(\mathrm{N}=215)$ and control $(\mathrm{N}=203)$ groups, 219 boys and 199 girls; average age: 13.2, SD: 0.43. Before and after the program, they completed a cyberbullying questionnaire, a self-efficacy scale, and an empathy scale.The results show a $12.4 \%$ decrease in students reporting of cyber- victimization and an increase in the percentage of bystanders who reported cyberbullying instances to teachers, an increase in students who ignored posts, and a decrease in the percentage of students sharing posts. Implications for further development of the intervention program and research are discussed.
\end{abstract}

Keywords: Intervention Program, Youth Cyberbullying, Bystanders 


\section{Introduction}

The current article presents a unique intervention program for coping with cyberbullying (CB), developed and assimilated among adolescents, focusing on the role and involvement of bystanders, as well as evaluation of the program's effectiveness according to various parameters. While most programs dealing with $\mathrm{CB}$ focus on prevention, deterrence, or support and treatment for victims (Cross et al., 2015; DeSmet et al., 2015; Gorem, 2016), the program presented in this study focuses on the role of bystanders in identifying CB victims and on ways to provide assistance to cyber- victims and strengthen their circle of support. This main thesis assumes such a program could improve the chances of assistance to the victims by helping the witnesses in real time.

\subsection{The Role of Bystanders in Cyberbullying Acts}

Over the last decade, many young people have come to view the internet as a powerful tool that enables communication with others as well as access to vital information (Ybarra \& Mitchell, 2004). Most adolescents today are members of various social networks, participating in forums, chat rooms, and blogs. Alongside the increase in the distribution of social networks and cellular telephones, CB has developed. Most programs dealing with CB focus on prevention, deterrence, or support and treatment for victims (Cross et al., 2015; DeSmet et al., 2015; Gorem, 2016), whereas the program presented in this study focuses on the role of bystanders in identifying $\mathrm{CB}$ victims and on ways to provide assistance to cyber victims and strengthen their circle of support. This main thesis assumes such a program could improve the chances of assistance to the victims by helping the witnesses in real time (Espelage et al., 2017; Olenik-Shemesh, Heiman, \& Eden, 2015).

The internet is a powerful tool that enables communication with others as well as access to essential information (Ybarra \& Mitchell, 2004), and most young people today are members of various social networks, take part in forums and chat rooms, create and react to blogs, play games on the internet, seek information, and so on (Barak, 2006). However, although most adolescents report positive experiences on the internet, it is likewise a source of negative experiences, such as deliberate abuse, violence, and harassment, behaviors that are all under the heading of $\mathrm{CB}$. Although considerable research over the past decade has investigated the nature of the phenomenon and its implications on adolescents' mental health (Brighhi et al., 2016; Olenik-Shemesh, Heiman, \& Eden, 2012; Ybarra \& Mitchell, 2004), few studies have devised intervention programs implemented among youth and accompanied by evaluation studies.

$\mathrm{CB}$ is a form of bullying that has been exposed and researched over the past decade, and that has shifted from the physical to the virtual dimension (Mason, 2008). It refers to an individual's or a group's use of various electronic means to carry out an act of violence, repeatedly and over time, toward a victim who cannot defend him-/herself (Smith et al., 2008),

Due to the high prevalence of computers and cellphones, CB takes place at any time and in any place and includes sending abusive text messages, pictures, or videos, shaming, 
photographing the victim without his or her consent and publicizing the pictures, or harming the victim by means of emails or instant messaging, often while maintaining the perpetrator's anonymity (Smith et al., 2008) Mason refers to CB as an anti-social behavior that is liable to undermine the school climate and affect those involved in it socially and educationally, cause psychological trauma to the cyber victims, and, in extreme cases, lead to suicide (Mason, 2008). Apart from the anonymity that usually characterizes CB, it also has a number of unique characteristics, such as wide dispersion to a large audience, a high level of accessibility, and an unequal relationship in which the perpetrator's advantage is manifested in technological knowledge and the ability to command the electronic media for the purposes of harassment on the internet. Exposing CB is difficult due to the lower tendency of cyber victims to report relative to victims of other kinds of bullying (Olenik-Shemesh \& Heiman, 2012). Although CB transcends sectors and age groups, it is most prevalent in adolescence. The ease of using social media intensifies this phenomenon and increases the risk of $\mathrm{CB}$ among youth (Ang, 2015).

CB acts involve three main types of participants: cyber victims, cyber perpetrators (cyberbullies), and bystanders. Cyberbullies harass, insult, and slander their victims by email, social media, blogs, discussion groups, online games, and so on. They can be physically weaker than the victim, and usually remain anonymous (Strom \& Strom, 2005; Mason, 2008), and their victims are not safe anywhere, even at home. Despite the severity of the abuse, the victims refrain from reporting it to adults, fearing their parents will prevent them from using the internet, which would lead to social isolation (Campbell, 2005), or for fearof retaliation atSchool or because they don't trust their parents or teachers can make things better.

The third group of participants - the bystanders - have received less attention in studies on CB. Because the victim usually refrains from telling adults what is happening, the bystanders are often the only ones who are aware of it and thus play a key role in CB episodes (Olenik-Shemesh, Heiman, \& Eden, 2015). Mason proposes distinguishing between two kinds of bystanders: those who are part of the problem and those who can be part of the solution. The former encourage and support the cyber perpetrators, or they watch what is happening without doing anything to help the cyber victim, whereas the bystanders who are part of the solution protest against the act of bullying, seek a way to help the victim or to stop the abuse, and support the cyber victim (Mason, 2008). Bystanders who support the victim have a significant influence on the $\mathrm{CB}$ act: Their support for the victim threatens the perpetrators' status, sometimes to the extent of stopping the CB act and weakening the effect of the abuse (Olenik-Shemesh et al., 2015).

In face-to-face bullying, the number of bystanders is usually relatively limited and their identity is usually clear and known to the perpetrator, the victim, and the other bystanders, because the bullying takes place in a defined, limited space. In CB acts, bullying extends beyond the space visible to the victim, and within a short time, it may be witnessed by many bystanders; nevertheless, most of them do not help the victim ((Wong-Lo \& Bullock, 2014). This kind of behavior may be explained by the "bystander effect" (Latane \& Darley, 1970), whereby, in acts of bullying and violence, and in $\mathrm{CB}$ in particular, the greater the number of bystanders, the less likely any one of them is to decide to take responsibility for the event and 
to help the victim, due to the diffusion of responsibility and feelings of guilt of the many people surrounding them (Wong-Lo \& Bullock, 2014). Like Wong-Lo and Bullock, Mason maintains that the key to preventing $\mathrm{CB}$ is to strengthen the bystanders and help them develop self-efficacy so they will intervene to help the cyber victim, and to develop empathy toward those hurt in order to prevent bystanders from joining the perpetrators (Mason, 2008).

For example, when bystanders choose to support the perpetrator, they sometimes may gain security and relationships in exchange. This exchange may reinforce and strengthen the perpetrator's acts. The bystanders may also play a major role in affecting the victims' experience and by sharing and assisting them. When they choose to assist, they provide social support to the cyber victims and may help reduce the victims' feelings of depression, anxiety, and loneliness (Twemlow \& Sacco, 2013). In addition, through providing help to the victim, they are able to threaten the perpetrator's status and may even make him or her stop the bullying act, and buffer the negative effects of the victimization (Hawkins, Pepler, \& Craig, 2001; Salmivalli, 2010; Wong-Lo \& Bullock, 2014).

Several studies have shown that bystanders who witness CB are more likely to act in favor of the perpetrator, strengthen his/her power, or choose to be passive, perhaps because of the anonymity of the cyberspace (Barlinska et al., 2013; McKenna, 2008). Salmivalli et al. (2011) argue that when bystanders in CB episodes choose to support the victim, they may play a key role in being able to prevent further harm. They may also influence others to contribute to stopping the act and decreasing its negative impacts.

In $\mathrm{CB}$ acts, the importance of bystanders is therefore central: They observe what is taking place and can defend the victim and reduce the abuse and its consequences; on the other hand, they can also join in the bullying and aggravate the abuse and consequences. Therefore, bystanders play a central role in dealing with the phenomenon of $\mathrm{CB}$, and the question is how they can be motivated to intervene on behalf of the cyber victim and thus help to reduce the dimensions of this phenomenon. Although in cases of face-to-face bullying, the nature of social networks and their distribution means the number of bystanders is small, due to the extensive distribution of $\mathrm{CB}$, most teenagers at one stage or another in their adolescence witness CB. Moreover, the literature shows most bystanders do not intervene on behalf of the victim, and sometimes they even join and assist the perpetrator (Mason, 2008; Kazerooni et al., 2018). In 2013, the National Center for Education Statistics in the US found one in every three students suffers from CB; however, the same survey showed that in the minority of cases in which the victim's friends intervened on his or her behalf, $\mathrm{CB}$ acts stopped $57 \%$ of the time. These findings indicate a need to develop educational programs that significantly influence bystanders and encourage them to intervene on behalf of the cyber victim, as well as prevent continued distribution of the abusive acts (Wong-Lo \& Bullock, 2014).

\subsection{The Bystander-Intervention Model}

Previous studies have found bystanders have a greater tendency to intervene in bullying when they regard the event as serious or when they are friends of the victim. The chance that the bystanders will intervene on behalf of the victim is also greater if they believe they are capable of dealing with the event successfully (if they have a high perception of self-efficacy). 
Moreover, bystanders tend to refrain from intervening when they are afraid of the perpetrator, when many bystanders are present (because everyone assumes someone else will help, i.e., diffusion of responsibility), when they do not know how they can help, and when they have a low sense of empathy (Twemlow \& Sacco, 2013; Bastiaensens et al., 2013; Barlinskw, Szuster, \& Winiewski, 2018; Olenik-Shemesh, Heiman, \& Eden, 2015).

Based on these findings, a unique intervention program was developed and implemented among adolescent student in junior high school. This program focuses on the bystanders and their potential role in $\mathrm{CB}$ events, in accordance with the conclusions presented by Wong-Lo and Bullock (2014).

The intervention program is based on a model for coping with $\mathrm{CB}$ that focuses on the bystanders, with the aim of developing bystanders' empathy toward the victims, equipping them with tools that will increase their sense of self-efficacy, and influencing and thereby motivating bystanders to intervene on behalf of the cyber victim. In the scope of the proposed study, the intervention program was developed and implemented among eighth-grade students by their teachers. Before and after the program, questionnaires were distributed that examined the program's contribution to the students' knowledge, their self-efficacy, their degree of empathy, and how they cope with CB. Moreover, the questionnaire examined the question of whether a change occurred in the prevalence of $\mathrm{CB}$ acts and in the behavior of bystanders during $\mathrm{CB}$ acts, after the program.

According to Wong-Lo and Bullock (2014), in such an intervention program, bystanders should undergo a process in which they learn to identify cases of $\mathrm{CB}$ in which intervention is necessary, as well as effective means to intervene, so that when they encounter cases of $\mathrm{CB}$, they will act to stop them, implementing the means of intervention they have been taught. That is, the goal of the intervention model is that the bystanders, who may be a part of the problem, will become a major part of the solution (Mason, 2008).

Another unique characteristic of this program is the fact that the homeroom teachers-as opposed to external mentors-present it. The literature has indicated many of the programs that are effective in preventing various risk behaviors in adolescence are delivered by teachers trained prior to the implementation of the intervention program. Studies show programs implemented by the educational staff/teachers are more effective than programs delivered by an external mentor or supervisor who is not part of the school staff (Lize et al., 2017; Gázquez, 2010; Waschbusch et al., 2018). Intervention programs delivered by school staff as part of the school's curriculumroutine have a longer-term chance of implementation and preservation. This finding is in contrast to interventions carried out by special personnel or outside of school (Waschbusch et al., 2018).

A study in Canada found that although most teachers expressed concern about CB, and although $36 \%$ of the students who took part in the study reported involvement in $\mathrm{CB}$, most educators were nevertheless unable to report concrete examples of cases of $\mathrm{CB}$ in their classes (Cassidy, Brown, \& Jackson, 2012). The researchers attribute this discrepancy to the technological gap between students and their teachers and the lack of training on this subject. The teachers who took part in the study expressed concern about $\mathrm{CB}$; however, they were 
unable to identify it or its severity when it actually occurred (Cassidy et al., 2012), and they lacked the tools to guide their students on how to cope. Another study, which examined how 451 educators (teachers, principals, and school counselors) handle $\mathrm{CB}$, found the majority of the educators who participated in the study (79\%) were not trained to cope with $\mathrm{CB}$ and its effects on students' functioning, scholastically, socially, and emotionally. Sixty-five percent of the teachers relate to events, and $14 \%$ were not involved at all. This study also points out the need to train teachers, while developing a program tailored according to their position, gender, school size, and age group (DeSmet et al., 2015). The technological gap between teachers and students derives from the fact that, as opposed to their teachers, students today are growing up surrounded by computers, video games, and cellphones, and they speak the language of technology as their "mother tongue" ("digital natives"; Prensky, 2001). Unlike their teachers and parents, they've become accustomed to receiving information rapidly. and nonlinearly, processing information from different sources in parallel, and coping with multitasking. They've also gotten used to instant gratification and frequent rewards (Prensky, 2001). To bridge and reduce this gap, and because teachers are responsible for what happens in class and have significant influence over their students, the need has arisen to develop educational programs, which should also include homeroom teachers, who will be instructed so they can teach suitable programs to their students (Cassidy et al., 2012). In addition, the fact that the contents are transferred by a non-external/unfamiliar entity has advantages.

The intervention program is based on the idea that, apart from coping with the CB phenomenon, the program, the educational program focuses on developing empathy and self-efficacy (Wong-Lo \& Bullock, 2014), which should increase the probability of assisting cyber victims. In both face-to-face bullying and cyberbullying the bystanders may have a significant role in influencing the situation. Yet, the current intervention program was built specifically for cyberbullying bystanders and on the basis of the unique characteristics of this type of bullying, such as the large and unknown distribution of the event and therefore the great greater potential of their actions as well as their ability to remain anonymous, no matter what course of action they choose to take.

\subsection{Empathy}

Empathy is related to one's ability to feel and share another person's emotions, and includes a wide range of emotional states, including experiencing emotions that match another person's emotions, caring for other people, and sensitivity to other peoples' thoughts and feelings (Schneider et al., 2005). Empathy refers to a person's awareness of the immediate sensitivity of the other and the individual's ability to identify and understand other people's feelings, their point of view, their world of experiences, and what feelings mean to them (Ang \& Goh, 2010). Some researchers maintain that a lack of ability to understand other people's feelings is related to bullying and that some bullies are not entirely aware of the influence of their behavior on their victims (Espelage et al., 2017). The research literature distinguishes between affective empathy, which is emotional arousal in a person, and cognitive empathy, which is a person's ability to predict another person's thoughts, feelings, or behavior objectively, without involvement of personal feelings. A study carried out in Singapore found low cognitive empathy is related to a high level of involvement in CB among boys, 
irrespective of the level of affective empathy, whereas among girls, low affective empathy is related to a high level of involvement in $\mathrm{CB}$, irrespective of cognitive empathy.

In view of these findings, including the development of empathy in educational programs that are intended to reduce $\mathrm{CB}$, while relating to both kinds of empathy and to the concept in general, is important (Ang \& Goh, 2010). The findings of a study carried out among college students in the US were similar (Doane, Pearson, \& Kelley, 2014). Wright, Wachs \& Harper (2018) have found that empathy moderated the positive relationship between bystanders of CB and depression, but not between bystanders of $\mathrm{CB}$ and anxiety. Little is known about the role of bystanders' empathy in $\mathrm{CB}$ events. Learning and developing empathy were found to contribute to reducing aggression and bullying in general and to reducing CB behaviors (Ang, 2015). Therefore, including the strengthening of skills in understanding others and developing empathy in intervention programs is important (Espelage et al., 2017).

\subsection{Self- Efficacy}

Self-efficacy refers to a person's beliefs about his or her abilities and the consequences of his or her efforts in different situations. These beliefs influence behavior, choices, efforts, coping ability, and persistence in different tasks. Self-efficacy is based on self-perceptions relating to knowledge, personal ability, execution, and control, and is related to specific future actions (Chen, 2010). Beliefs relating to self-efficacy are based on information derived from four possible sources: personal experience, alternative experiences, verbal persuasion, and physical and emotional reactions. This information develops into cognitive knowledge with an emotional dimension that influences a person's ability to realize his or her abilities or not(Chen, 2010). The research literature also distinguishes between affective efficacy and social efficacy. An examination of the association between the perception of social self-efficacy and witnessing bullying found that the higher the perceived social self-efficacy of the bystanders, the more they expressed empathy and the greater their desire to help the victims. Additionally, the chance of their intervening on behalf of the victims and trying to stop the bullying increased (Heiman, Olenik-Shemesh, \& Eden, 2014b).

\subsection{Key-Principles of the CB Bystanders' Intervention Program}

In accordance with the bystander-intervention model proposed by Wong-Lo and Bullock (2014), the authors developed and implemented over a period of three months an intervention program among 418 eighth-grade students in 12 classes in a junior high school in the center of Israel. Half of the eighth-grade classes took part in the intervention program (an experimental group), and half did not, but filled in the questionnaires (serving as the control group). An educational program was developed according to the model, in which the students underwent a process corresponding to the stages of the intervention model and prepared outputs that reflected what they learned. The program consisted of six instructional experiential meetings: (1) noticing the bullying event: a game and joint work in groups on the subject of defining the concept of "cyberbullying;" (2) interpreting the event as an emergency: work in groups about a case of bullying while identifying and emphasizing the abuse of the victim; (3) taking responsibility for the event: work in groups, role play using mime; (4) knowledge about effective means of intervention: working with authentic case stories and 
proposing solutions in groups; (5) actual intervention by the bystander on behalf of the victim: discussion in groups and plenary discussion on means of intervention, advantages, and disadvantages; and (6) summing up: preparing a summarizing exhibition on the subject.

In more detail, the first lesson dealt with the definition of $\mathrm{CB}$ and included an opening game followed by creative work in groups on defining and understanding the concept. The class students' definition was concluded and formulated as to the definition of the concept and the participants in $\mathrm{CB}$ acts (victim, bully and bystanders). The second lesson dealt with identifying the $\mathrm{CB}$ act as an emergency situation. The students watched a video that presented an episode of CB following the scenes they have studied to identify and mark the stage in which the victim was in, concluded in a class discussion. The third lesson dealt with taking responsibility for the event by the bystander, discussion along preparation of pantomime sequences by the students, presenting two situations in which a person is in distress following $\mathrm{CB}$ acts. In the first situation no one helped the cyber victim and in the second situation one of the group members helps. To conclude, a class discussion was held on the issue of responsibility and acting accordingly. The fourth lesson dealt with imparting knowledge about effective methods of intervention. The students were asked to think about ways of help by the witnesses and to show the class how a CB episode ends differently after the intervention of the witnesses. The fifth lesson dealt with an actual intervention. In this lesson, the class discussed the response possibilities of the bystanders who came up in the previous lesson and the other responses raised in the plenum and discussed the advantages and disadvantages of each way of response. In the sixth lesson the prepared an exhibition in small groups (2-4 students), focusing on an advertisement on the subject of "Cyberbullying! We will stop it." The students could prepare a poster, presentation, video or any other creative product they think about through the messages learned throughout the program. The exhibition was presented to the parents and education staff at a meeting held in the evening.

After undergoing training on the topic, the homeroom teachers taught the intervention program to the students. In the framework of these meetings, the program has two main aims. The first is to teach students effective means of intervention that will increase their chance of intervening while being bystanders to CB events, implementing the tools they have acquired in the program and assisting the victims in real time. The second is to increase the students' empathy toward the cyber victims, and their sense of self-efficacy.

The proposed program is unique in focusing on the bystanders in a way that is intended to strengthen them and influence them to intervene on behalf of the cyber victim and to prevent the abuse from continuing and spreading. The educational program is intended mainly to influence students' perceptions and views, to develop social capabilities, as well as strengthen empathy and self-efficacy among potential bystanders. In this study, the homeroom teachers, who knew the students, taught the program, which was spread over a number of weeks with the aim of achieving effective internalization of the messages among the participating students.

Accordingly, the program consisted of two main stages: In the first stage, the teachers underwent a course of lessons in which they also experimented with some of the lesson 
content planned for the students. The teachers' training emphasized imparting the concepts of digital literacy and social networks. The teachers' course was taught in four study units of an hour and a half each, for a total of six hours. In the second, central stage, the teachers implemented the program among their students in classes. The students' course, as noted above, consisted of six lessons: five focusing on one of the stages in the intervention model, and an additional lesson for discussion and summing up. This educational program has four unique advantages:

1. It is based on the bystander intervention model, which was tested effectively in dealing with face-to-face bullying and underwent adaptation for dealing with CB (Wong-Lo \& Bullock, 2014).

2. The program includes a training program that imparts knowledge and skills to the school's teaching staff, so that the program will also be able to take place at school classes after the study ends.

3. The program is taught to students by the school staff, who know the students, rather than by someone external.

4. The program is spread over a number of weeks, which is likely to create better internalization of the messages than similar programs often taught in a short, one-time format.

In light of the above, in order to evaluate the effectiveness of the program, we have re-examined the prevalence of cyber victimization, bystanders behaviors and level of empathy and self-efficacy, assuming that there will be a change, following the participation in the program:

\section{Research Aims and Questions}

The main aim of the current study was to develop, assimilate, and evaluate the effectiveness of an intervention program for students dealing with $\mathrm{CB}$, based on the assumption that strengthening self-efficacy and developing empathy, particularly among bystanders who witness $\mathrm{CB}$, will lead to a reduction in involvement in $\mathrm{CB}$ among teenagers.

In this framework, the following research questions were examined:

1. What is the difference in the prevalence of cyber victimization before and after participation in the program, hypothesizing that participation in the program will lead to a decrease in the prevalence of $\mathrm{CB}$ acts?

2. Do bystanders' behaviors in CB episodes before and after the intervention program differ?

3. Does the level of students' sense of self-efficacy before and after the program differ, hypothesizing an increase in self-efficacy after the program?

4. Does the level of students' feelings of empathy before and after the program differ, hypothesizing an increase in empathy after the program? 
Background variables (gender, parents' education), characteristics of use of the internet (duration, content, involvement in cyber violence), and variables of empathy and self-efficacy were also examined.

\section{Method}

\subsection{Participants}

The study included 418 eighth-grade students (219 boys and 199 girls; mean age=13.2) in a junior high in the center of Israel, medium-high socioeconomic level. All 12 classes in the 8th group in that school participated in the study. Randomly, six classes were utilized as the experimental group, and six classes as control group. Random addignment was used The intervention (experimental) group included 215 students (108 boys and 107 girls), and the control group included 203 students (111 boys and 92 girls). Participants average age: 13.2, SD: 0.43 .

\subsection{Procedure and Study Design}

Before starting the study (implementation and evaluation), an ethical approval was provided to Authors from the Ethical Board of the Ministry of Education (No- 9560). The approval was presented to the school principal who approved her school participation in the study. According to the directives of the Ethics Committee of the Chief Scientist of the Ministry of Education, the teachers participating in the study have received an explanation letter about the intervention program and were asked to sign a letter of consent for participation .In addition, the students and their parents received a letter in which they were given the opportunity to object to the participation in the study by a letter of objection.

The study design consisted of four stages:

1. In the beginning of the school year, teacher training was held among the teachers of the 8th grade in school, which included knowledge instruction regarding cyberbullying, and ways that bystanders can intervene and help,

2. Few days before starting the implementation of the intervention program. all participants completed three questionnaires: A Cyberbullying questionnaire, a self-efficacy scale, and an empathy scale - distribution of questionnaires to all the research participants (students in the experimental classes and the control classes).

3. The implementation of the intervention program over a period of 3 month through six meetings, only in the experimental classes, by their teachers.

4. After the completion of the intervention program, distribution of the same questionnaires to students.

\subsection{Measures}

3.3.1 Cyberbullying Questionnaire (Smith et al., 2008).

The questionnaire consists of 22 items on a 5-point scale, referring to several categories: 
using the internet, being cyberbullied, emotions and behavioral reaction; cyber-witnessing and the students' cyber-witness reactions. The questionnaire includes definitions of $\mathrm{CB}$ and consists of questions regarding victimization, perpetration, and being bystanders to $\mathrm{CB}$ episodes. Construct validity is evidenced by previous studies (Brighi et al., 2012; Smith et al., 2008; Steffgen et al., 2011). The questionnaire was translated from English into Hebrew and then back-translated by three judges to check accuracy.

\subsubsection{Self-efficacy Questionnaire (Muris, 2001).}

The questionnaire contains 13 items relating to two areas-social and emotional-accompanied by answer scales ranging from "not at all" (1) to "very well" (5), with the higher score reflecting a higher sense of self-efficacy. An example from the social self-efficacy scale is "Can you maintain social relationships with other students?" (Cronbach's Alpha = 0.73). An example from the emotional self-efficacy scale is "Can you control your feelings?" (Cronbach's alpha $=.86$ ). Cronbach's alpha for the entire scale for this sample was .86.

\subsubsection{Empathy Questionnaire (Mehrabian \& Epstein, 1972).}

The purpose of this questionnaire is to examine the subject's degree of empathy. The questionnaire includes 33 items describing emotional states, and subjects respond using a 9-point scale, ranging from strong agreement (4+) to very strong disagreement (4) The overall score is calculated by summing the item grades, with some items needing to be reversed.The higher the score, the higher the level of empathy.

\subsubsection{Evaluation Questionnaire (Heiman \&Olenik-Shemesh, 2018, internal document).}

The questionnaire includes two parts: nine statements on a 5-point scale, ranging from "not agree" (1) to "strongly agree (5) ".The score of the program evaluation is calculated by summing up the responses, so that a higher score reflects higher satisfaction with the intervention program. The second part includes three open questions in which the subject is asked to write what he or she learned from the program program.

\section{Results-Program Evaluation}

The study comprised 418 (219 boys and 199 girls; average age: 13.2, SD: 0.43) participants in six experimental classes and six control classes, 219 boys and 199 girls. In the first part of the questionnaire, the students were asked about their use of the internet. Results indicate that most of the students (358 participants) reported having a cell phone (85.6\%), and only two students reported having no access to the internet. In the second part of the questionnaire, the students were asked if and how they had been cyber victims. Forty-eight percent of the participants reported being cyberbullied during the last year.

Table 1 shows the data on reporting CB, before and after the program. 
Table 1. Kinds of Cyberbullying Acts

\begin{tabular}{|c|c|c|c|c|c|c|c|}
\hline \multirow[b]{3}{*}{ Kind of CB Act } & $\begin{array}{l}\text { Experin } \\
\text { group } \\
\mathbf{n}=\mathbf{2 1 5}\end{array}$ & & $\begin{array}{l}\text { Control } \\
\text { group } \\
\mathbf{n}=\mathbf{2 0 3}\end{array}$ & & \multirow[t]{3}{*}{$\begin{array}{l}\chi^{2} \text { group } \\
\text { (experimenatl/ } \\
\text { control) }\end{array}$} & \multirow{3}{*}{$\begin{array}{l}\chi^{2} \\
\text { time } \\
\text { (before/a } \\
\text { fter) }\end{array}$} & \multirow{3}{*}{$\begin{array}{l}\chi^{2} \\
\text { grou } \\
\text { p X } \\
\text { time }\end{array}$} \\
\hline & \multicolumn{4}{|c|}{ Average (SD) } & & & \\
\hline & Before & After & Before & After & & & \\
\hline \multirow[t]{2}{*}{ Victim - summary } & .47 & .36 & .48 & .40 & .12 & $14.06 * * * *$ & .04 \\
\hline & $(.04)$ & $(.04)$ & (.04) & $(.04)$ & & & \\
\hline \multirow[t]{2}{*}{ Name-calling } & .31 & .24 & .29 & .28 & .07 & 1.4 & 1.2 \\
\hline & $(.03)$ & $(.04)$ & $(.03)$ & $(.03)$ & & & \\
\hline \multirow[t]{2}{*}{ Spread rumors about you } & .16 & .12 & .14 & .13 & .01 & .604 & .538 \\
\hline & $(.02)$ & $(.03)$ & $(.03)$ & $(.03)$ & & & \\
\hline \multirow[t]{2}{*}{ Mocked your appearance } & .19 & .19 & .23 & .2 & .59 & .34 & .51 \\
\hline & $(.03)$ & $(.03)$ & $(.03)$ & $(.03)$ & & & \\
\hline \multirow{2}{*}{$\begin{array}{l}\text { Tried to cause your friends } \\
\text { not to like you }\end{array}$} & .15 & .12 & .11 & .11 & .48 & .71 & .41 \\
\hline & $(.02)$ & $(0.3)$ & $(.02)$ & $(.02)$ & & & \\
\hline \multirow{2}{*}{$\begin{array}{l}\text { Tried to damage your } \\
\text { reputation }\end{array}$} & .26 & .25 & .26 & .22 & .20 & 1.11 & .25 \\
\hline & $(.03)$ & $(.03)$ & $(.03)$ & $(.03)$ & & & \\
\hline \multirow{2}{*}{$\begin{array}{l}\text { Tried to cause you to feel } \\
\text { bad about yourself }\end{array}$} & .29 & .23 & .34 & .23 & .27 & $9.19 * * *$ & .72 \\
\hline & $(.03)$ & $(.03)$ & $(.04)$ & $(.03)$ & & & \\
\hline \multirow{2}{*}{$\begin{array}{l}\text { Distributed your } \\
\text { photos/video }\end{array}$} & .05 & .07 & .11 & .04 & .09 & 1.63 & $5.17 *$ \\
\hline & $(.02)$ & $(.02)$ & $(.02)$ & $(.01)$ & & & \\
\hline \multirow[t]{2}{*}{ Threatened to harm you } & .09 & .09 & .11 & .07 & .01 & 1.39 & .69 \\
\hline & $(.02)$ & $(.02)$ & $(.02)$ & $(.02)$ & & & \\
\hline \multirow[t]{2}{*}{ Pestered/harassed you } & .16 & .14 & .17 & .10 & .37 & 3.51 & 1.32 \\
\hline & $(.02)$ & $(.03)$ & $(.03)$ & $(.02)$ & & & \\
\hline \multirow{2}{*}{$\begin{array}{l}\text { Threatened to harm your } \\
\text { friends /family physically }\end{array}$} & .02 & .04 & .03 & .02 & .29 & .05 & .98 \\
\hline & $(.01)$ & $(.02)$ & $(.01)$ & $(.01)$ & & & \\
\hline \multirow{2}{*}{$\begin{array}{l}\text { Tried to make sexual } \\
\text { advances to you }\end{array}$} & .09 & .08 & .06 & .06 & 1.21 & .04 & .25 \\
\hline & $(.02)$ & $(.02)$ & $(.02)$ & $(.02)$ & & & \\
\hline \multirow[t]{2}{*}{ Sent you rude pictures } & .07 & .07 & .09 & .05 & .00 & 1.78 & 1.23 \\
\hline & $(.02)$ & $(.02)$ & $(.02)$ & $(.02)$ & & & \\
\hline \multirow{2}{*}{$\begin{array}{l}\text { Sent negative messages } \\
\text { supposedly from you }\end{array}$} & .05 & .07 & .08 & .06 & .33 & .21 & 1.56 \\
\hline & $(.01)$ & $(.02)$ & $(.02)$ & $(.02)$ & & & \\
\hline \multirow[t]{2}{*}{ Sent you to Coventry } & .04 & .03 & .06 & .05 & .95 & .31 & .00 \\
\hline & $(.01)$ & $(.01)$ & $(.02)$ & $(.02)$ & & & \\
\hline
\end{tabular}

$* p<.05, * * p<.01, * * * p<.001$, range of the answers: $0-1$ 


\section{Macrothink}

International Journal of Education

ISSN 1948-5476

2019, Vol. 11, No. 2

Table 1 shows that in both the experimental and control groups, the percentage of students who reported cyber victimization during the past year, in any way or with any frequency, decreased. However, the decrease was bigger in the experimental group than in the control group. Chi-squared test have shown a significant difference between cyber victimization before and after the program, $\chi^{2}(2,416)=13.9, p<0.001$. No significant differences in interactions were found.

Focusing on the experimental group, the greatest decrease occurred in the following kinds of abuse: name-calling, trying to make you feel bad about yourself, spreading rumors and trying to cause your friends not to like you. No significant change was found in the other kinds of abuse. Analysis of the frequency of the abuse in Table 1 shows the most frequent kinds of abuse are name-calling (31\%), trying to cause you to feel bad about yourself (29\%), and trying to damage your reputation (26\%). In addition, it was found that most frequent kinds of $\mathrm{CB}$ are the most accessible ones. The results show that $54.2 \%$ of the students in the experimental group who were victims and $51.5 \%$ of the students in the control group who were victims reported they were abused on WhatsApp.

To examine the change in the students' emotions and behaviors, students who reported being cyber victims were asked about their emotions and reaction patterns. Table 2 presents the distribution of emotions and reaction patterns reported by cyber victims (in percentages).

Analysis of the emotions and behaviors of the cyber victims (Table 2) shows that after the intervention program, some of the parameters increased significantly. In the experimental group, those increases occurred mainly in the following reactions: "Behaving differently at home" and "Behaving differently with my friends". They also occurred in the following emotions: worry and frustration. In the control group, the main increase in emotion occurred for frustration. The significant main increases in behavior occurred for "Behaving differently at home" and "Behaving differently with my friends". 
Table 2. Emotions and Reaction Patterns of Cyber-Victims Before and After the Program $(\mathrm{N}=$ 219)

\begin{tabular}{|c|c|c|c|c|c|c|c|}
\hline \multirow{3}{*}{$\begin{array}{l}\text { Emotion/ } \\
\text { Behavior }\end{array}$} & \multicolumn{2}{|c|}{$\begin{array}{l}\text { Experimental } \\
\text { group }\end{array}$} & \multicolumn{2}{|c|}{$\begin{array}{l}\text { Control } \\
\text { group }\end{array}$} & \multirow{3}{*}{$\begin{array}{l}\chi^{2} \text { group } \\
\text { (experimental } \\
\text { / control) }\end{array}$} & \multirow{3}{*}{$\begin{array}{l}\chi^{2} \\
\text { time } \\
\text { (before/after) }\end{array}$} & \multirow[t]{3}{*}{$\begin{array}{l}\chi^{2} \\
\text { group } X \text { time }\end{array}$} \\
\hline & \multicolumn{4}{|c|}{ Average (SD) } & & & \\
\hline & Before & After & Before & After & & & \\
\hline \multirow[t]{2}{*}{ Worry } & .57 & .69 & .46 & .60 & 1.86 & $3.84 * *$ & .00 \\
\hline & $(.06)$ & $(.08)$ & $(.06)$ & $(.07)$ & & & \\
\hline \multirow[t]{2}{*}{ Stressed } & .53 & .58 & .44 & .62 & .09 & 3.99 & 1.10 \\
\hline & $(.06)$ & $(.08)$ & $(.06)$ & $(.07)$ & & & \\
\hline \multirow[t]{2}{*}{ Anger } & .69 & .75 & .67 & .82 & .22 & 3.25 & .69 \\
\hline & $(.06)$ & $(.07)$ & $(.05)$ & $(.06)$ & & & \\
\hline \multirow[t]{2}{*}{ Frustration } & .54 & .65 & .43 & .78 & .06 & $14.18 * * *$ & $4.22 *$ \\
\hline & $(.06)$ & $(.08)$ & $(.06)$ & $(.06)$ & & & \\
\hline \multirow[t]{2}{*}{ Loss of appetite } & .29 & .23 & .20 & .31 & .01 & .26 & 2.47 \\
\hline & $(.06)$ & $(.07)$ & $(.05)$ & $(.07)$ & & & \\
\hline \multirow[t]{2}{*}{ Depressive mood } & .67 & .47 & .44 & .67 & .02 & .05 & $13.39 * * *$ \\
\hline & $(.06)$ & (.08) & $(.06)$ & $(.07)$ & & & \\
\hline Academic & .30 & .42 & .24 & .29 & 1.75 & 2.46 & .37 \\
\hline problems & $(.06)$ & $(.07)$ & $(.05)$ & $(.08)$ & & & \\
\hline Sleep & .43 & .34 & .30 & .32 & .96 & 1.83 & .76 \\
\hline difficulties & $(.07)$ & (.06) & $(.05)$ & $(.06)$ & & & \\
\hline Behaving & .39 & .59 & .39 & .50 & .28 & $7.32 * * *$ & .75 \\
\hline differently with & $(.06)$ & $(.08)$ & $(.06)$ & $(.07)$ & & & \\
\hline \multicolumn{8}{|l|}{ my friends } \\
\hline Behaving & .28 & .50 & .31 & .43 & .03 & $9.22 * * *$ & .77 \\
\hline differently at & $(.06)$ & $(.08)$ & $(.05)$ & $(.07)$ & & & \\
\hline \multicolumn{8}{|l|}{ home } \\
\hline Do not want to go & .26 & .51 & .30 & .31 & .99 & 4.95 & 4.38 \\
\hline to school/school & $(.05)$ & $(.08)$ & $(.05)$ & $(.07)$ & & & \\
\hline absence & & & & & & & \\
\hline
\end{tabular}

$* p<.05, * * p<.01, * * * p<.001$, range of the answers: $0-1$.

In the third part of the questionnaire, the students were asked if they were bystanders to $\mathrm{CB}$ acts, and if so, how they reacted. Table 3 shows the reports of CB bystanders according to the kind of abuse they witnessed. 
Table 3. Bystanders to CB According to the Kind of Abuse $(\mathrm{N}=418)$

\begin{tabular}{|c|c|c|c|c|c|c|c|}
\hline \multirow[b]{3}{*}{ Kind of Abuse } & \multirow{2}{*}{\multicolumn{2}{|c|}{$\begin{array}{l}\text { Experimental } \\
\text { group } \\
\text { Average }(\mathrm{SD})\end{array}$}} & \multicolumn{2}{|l|}{$\begin{array}{l}\text { Control } \\
\text { group }\end{array}$} & \multirow{3}{*}{$\begin{array}{l}\chi^{2} \text { group } \\
\text { (experimental/ } \\
\text { control) }\end{array}$} & \multirow{3}{*}{$\begin{array}{l}\chi^{2} \\
\text { time } \\
\text { (before/ } \\
\text { after) }\end{array}$} & \multirow{3}{*}{$\begin{array}{l}\chi^{2} \\
\text { group } x \\
\text { time }\end{array}$} \\
\hline & & & & & & & \\
\hline & Before & After & Before & After & & & \\
\hline $\begin{array}{l}\text { Was a bystander - } \\
\text { summary }\end{array}$ & $\begin{array}{l}.66 \\
(.03)\end{array}$ & $\begin{array}{l}.60 \\
(.04)\end{array}$ & $\begin{array}{l}.76 \\
(.03)\end{array}$ & $\begin{array}{l}.60 \\
(.04)\end{array}$ & 1.81 & $12.38 * * *$ & 2.65 \\
\hline $\begin{array}{l}\text { Called them } \\
\text { names }\end{array}$ & $\begin{array}{l}.61 \\
(.03)\end{array}$ & $\begin{array}{l}.57 \\
(.04)\end{array}$ & $\begin{array}{l}.70 \\
(.03)\end{array}$ & $\begin{array}{l}.56 \\
(.04)\end{array}$ & 1.03 & $7.54^{* * * *}$ & 2.35 \\
\hline $\begin{array}{l}\text { Spread rumors } \\
\text { about them }\end{array}$ & $\begin{array}{l}.40 \\
(.03)\end{array}$ & $\begin{array}{l}.39 \\
(.04)\end{array}$ & $\begin{array}{l}.50 \\
(.04)\end{array}$ & $\begin{array}{l}.33 \\
(.04)\end{array}$ & .17 & $7.43^{* * *}$ & $6.16^{*}$ \\
\hline $\begin{array}{l}\text { Mocked their } \\
\text { appearance }\end{array}$ & $\begin{array}{l}.51 \\
(.03)\end{array}$ & $\begin{array}{l}.44 \\
(.04)\end{array}$ & $\begin{array}{l}.57 \\
(.04)\end{array}$ & $\begin{array}{l}.48 \\
(.04)\end{array}$ & 1.58 & $6.28 *$ & .04 \\
\hline $\begin{array}{l}\text { Tried to damage } \\
\text { their reputation }\end{array}$ & $\begin{array}{l}.50 \\
(.03)\end{array}$ & $\begin{array}{l}.42 \\
(.04)\end{array}$ & $\begin{array}{l}.54 \\
(.04)\end{array}$ & $\begin{array}{l}.42 \\
(.04)\end{array}$ & .203 & $9.69^{* * *}$ & .34 \\
\hline $\begin{array}{l}\text { Distributed their } \\
\text { photos/video }\end{array}$ & $\begin{array}{l}.15 \\
(.02)\end{array}$ & $\begin{array}{l}.19 \\
(.03)\end{array}$ & $\begin{array}{l}.25 \\
(.03)\end{array}$ & $\begin{array}{l}.19 \\
(.03)\end{array}$ & 2.31 & .07 & 3.1 \\
\hline $\begin{array}{l}\text { Pestered/ } \\
\text { harassed them }\end{array}$ & $\begin{array}{l}.30 \\
(.03)\end{array}$ & $\begin{array}{l}.29 \\
(.04)\end{array}$ & $\begin{array}{l}.35 \\
(.04)\end{array}$ & $\begin{array}{l}.28 \\
(.03)\end{array}$ & .26 & 1.36 & .93 \\
\hline $\begin{array}{l}\text { Threatened to } \\
\text { harm them }\end{array}$ & $\begin{array}{l}.29 \\
(.03)\end{array}$ & $\begin{array}{l}.26 \\
(.04)\end{array}$ & $\begin{array}{l}.24 \\
(.03)\end{array}$ & $\begin{array}{l}.16 \\
(.03)\end{array}$ & $4.75^{*}$ & $4.57 *$ & 1.08 \\
\hline $\begin{array}{l}\text { Sent them to } \\
\text { Coventry }\end{array}$ & $\begin{array}{l}.15 \\
(.02)\end{array}$ & $\begin{array}{l}.16 \\
(.03)\end{array}$ & $\begin{array}{l}.21 \\
(.03)\end{array}$ & $\begin{array}{l}.12 \\
(.02)\end{array}$ & .03 & 2.60 & $4.56^{*}$ \\
\hline
\end{tabular}

$* p<.05, * * p<.01, * * * p<.001$, range of the answers: $0-1$.

Analysis of the data in Table 3 shows a decrease in the experimental group in the number of the students who reported witnessing CB in the past year, as well as in the control group. Focusing on the experimental group, the biggest decrease occurred in witnessing the following kinds of abuse: trying to damage their reputation (50\% vs. $42 \%$ ) and mocking their appearance ( $51 \%$ vs. $44 \%$ ). In the chi-squared test, a comparison of abuse before and after the program shows a significant decrease, both in the experimental group and in the control group: $\chi^{2}(2,416)=12.19, p<0.001$. No significant differences in interactions were found.

Table 4 shows the data on the reported actions of students who were bystanders to CB acts.

Table 4 shows that in the experimental group, the percentage of bystanders who reported to teachers increased significantly. There was also increase in the percentage of the bystanders who ignored it, a decrease in telling the friend and in "liking" the abusive post, bit these differences were not significant. The control group experienced a non-significant increase in the number of bystanders who ignored the $\mathrm{CB}$ act, and a decrease in the percentage of bystanders who told the friend, who were cyber victism and in attacking the perpetrator, and sharing the post. 
In addition, we also hypothesized an increase in self-efficacy and sense of empathy after the program within the experimental-group participants. First we have studied the extent to which difference scores of the cyberbullying survey are predicted by the individual-difference variables: self-efficacy and empathy). For that purpose we have run a regression model that revealed a significant effect $\left(\chi_{(2)}^{2}=25.96, \mathrm{R}^{2}=.29\right)$.

We performed T-tests to examine the significance of the differences between the level of empathy and self-efficacy in the experimental group, before and after the intervention program was implemented. Results have shown the level of self-efficacy did not increase significantly, whereas the level of empathy increased in the experimental group after participation in the intervention program, particularly among those whose level of empathy was low prior to the program . The level of empathy prior to the program $(\mathrm{M}=97.14, \mathrm{SD}=$ $8.05)$ was lower than after the program $(\mathrm{M}=99.89, \mathrm{SD}=10.24)$. This difference was found to be significant, $t(66)=2.43, p<0.01$. In the experimental group whose level of empathy was high before the program, no change occurred.

Table 4. Bystanders' Reactions to CB Act $(\mathrm{N}=314)$

\begin{tabular}{|c|c|c|c|c|c|c|c|}
\hline \multirow[b]{3}{*}{ Bystanders' Reaction } & \multicolumn{2}{|c|}{$\begin{array}{l}\text { Experimental } \\
\text { group }\end{array}$} & \multicolumn{2}{|l|}{$\begin{array}{l}\text { Control } \\
\text { group }\end{array}$} & \multirow{3}{*}{$\begin{array}{l}\chi^{2} \text { group } \\
\text { (experi-m } \\
\text { ental/ } \\
\text { control) }\end{array}$} & \multirow{3}{*}{$\begin{array}{l}\chi^{2} \\
\text { time } \\
\text { (before/ } \\
\text { after) }\end{array}$} & \multirow{3}{*}{$\begin{array}{l}\chi^{2} \\
\text { group } \mathrm{X} \\
\text { time }\end{array}$} \\
\hline & \multicolumn{4}{|c|}{ Average (SD) } & & & \\
\hline & Before & After & Before & After & & & \\
\hline I shared the post & $\begin{array}{l}.07 \\
(.02)\end{array}$ & $\begin{array}{l}.05 \\
(.02)\end{array}$ & $\begin{array}{l}.06 \\
(.02)\end{array}$ & $\begin{array}{l}.03 \\
(.02)\end{array}$ & .46 & 1.4 & .16 \\
\hline I "liked" it & $\begin{array}{l}.07 \\
(.02)\end{array}$ & $\begin{array}{l}.05 \\
(.02)\end{array}$ & $\begin{array}{l}.07 \\
(.02)\end{array}$ & $\begin{array}{l}.04 \\
(.02)\end{array}$ & .00 & 1.22 & 0.3 \\
\hline I asked them to stop & $\begin{array}{l}.59 \\
(.04)\end{array}$ & $\begin{array}{l}.59 \\
(.05)\end{array}$ & $\begin{array}{l}.58 \\
(.04)\end{array}$ & $\begin{array}{l}.52 \\
(.04)\end{array}$ & .62 & .41 & .40 \\
\hline $\begin{array}{l}\text { I ignored the } \\
\mathrm{CB} \text { act }\end{array}$ & $\begin{array}{l}.60 \\
(.04)\end{array}$ & $\begin{array}{l}.66 \\
(.05)\end{array}$ & $\begin{array}{l}.64 \\
(.04)\end{array}$ & $\begin{array}{l}.71 \\
(.04)\end{array}$ & .89 & 2.56 & .05 \\
\hline $\begin{array}{l}\text { I attacked the cyber } \\
\text { perpetrator }\end{array}$ & $\begin{array}{l}.35 \\
(.04)\end{array}$ & $\begin{array}{l}.32 \\
(.05)\end{array}$ & $\begin{array}{l}.43 \\
(.04)\end{array}$ & $\begin{array}{l}.32 \\
(.05)\end{array}$ & .60 & 2.74 & 1.10 \\
\hline $\begin{array}{l}\text { I told the friend who } \\
\text { was cyberbullied }\end{array}$ & $\begin{array}{l}.60 \\
(.04)\end{array}$ & $\begin{array}{l}.55 \\
(.05)\end{array}$ & $\begin{array}{l}.62 \\
(.04)\end{array}$ & $\begin{array}{l}.55 \\
(.05)\end{array}$ & .00 & 2.14 & .01 \\
\hline I told my parents & $\begin{array}{l}.32 \\
(.04)\end{array}$ & $\begin{array}{l}.32 \\
(.05)\end{array}$ & $\begin{array}{l}.29 \\
(.04)\end{array}$ & $\begin{array}{l}.23 \\
(.04)\end{array}$ & 1.61 & .71 & .68 \\
\hline I told the teacher & $\begin{array}{l}.17 \\
(.03)\end{array}$ & $\begin{array}{l}.23 \\
(.04)\end{array}$ & $\begin{array}{l}.21 \\
(.04)\end{array}$ & $\begin{array}{l}.14 \\
(.03)\end{array}$ & .52 & .06 & $3.82 *$ \\
\hline I laughed at it & $\begin{array}{l}.13 \\
(.03)\end{array}$ & $\begin{array}{l}.15 \\
(.04)\end{array}$ & $\begin{array}{l}.24 \\
(.03)\end{array}$ & $\begin{array}{l}.21 \\
(.04)\end{array}$ & .74 & 1.94 & .42 \\
\hline $\begin{array}{l}\text { I wrote down the } \\
\text { incidents }\end{array}$ & $\begin{array}{l}.06 \\
(.02)\end{array}$ & $\begin{array}{l}.09 \\
(.03)\end{array}$ & $\begin{array}{l}.03 \\
(.02)\end{array}$ & $\begin{array}{l}.03 \\
(.02)\end{array}$ & 2.42 & .29 & .32 \\
\hline
\end{tabular}

$* p<.05, * * p<.01, * * * p<.001$, range of the answers: $0-1$. 
We also examined the correlation between cyber victims and bystanders and found a significant positive correlation between the variables. In the experimental group $\left(\mathrm{r}=.396^{* *}\right.$, $p<.005), 82.8 \%$ of the victims were also bystanders who witnessed abuse, and in the control group $(\mathrm{r}=.332 * *, p<.005), 87.5 \%$ were. For all the findings, in order to reduce the chances of obtaining false-positive results, a Bonferroni correction was used for inflated experiment-wise alpha, to correct or protect from Type I error.

\section{Discussion, Limitations and Future Implications}

\subsection{Discussion}

Several studies in the past decade have shown $\mathrm{CB}$ has negative implications on the well-being and mental health of children and adolescents (Almenayes, 2017; Bilic, 2013; Brighi et al., 2012; Olenik-shemesh, Heiman, \& Eden, 2012). Educators, researchers, decision-makers, parents, and students share the interest in preventing and reducing this phenomenon (Dietze et al., 2012; Lee, Kim \& Kim, 2015; Ttofi \& Farrington, 2011). Resource limitations and the wide range of options offered by external professionals to the education system and to government ministries involved in the formulation of prevention policies require knowledge of effective prevention programs and strategies. The current study presented a unique intervention program at a group or classroom level through a series of structured meetings aimed at preventing and reducing $\mathrm{CB}$ when focusing on the potential power of bystanders to $\mathrm{CB}$ episodes.

The main aim of the present study was to advance a program for adolescent students on coping effectively with CB. Previous studies have found that a third of junior high school students have been cyber victims and that the percentage of victims increases every year (Wong-Lo \& Bullock, 2014). The present study found that more than half of the students (53.2\%) reported having been cyber victims in some way before the intervention program, thus showing the importance of providing an educational solution for this problem by expanding and improving programs available to the teaching staff. The current study have focused in an intervention program for coping with cyberbullying, focused on the role of bystanders, based on the bystander model. The Research literature in the field shows that most of the intervention programs for coping with $\mathrm{CB}$ address cyber-victims. However, the current program focuses on the role of bystanders, and their potential role in coping with the phenomenon.

As described above, In CB acts, the importance of bystanders is central and they may affect the act, to continue and even to stop. The current intervention program, based on the bystanders' intervention model was designed and implemented in order to help motivated the bystanders to intervene on behalf of the cyber victim, thus help to reduce the dimensions of this phenomenon (Wong-Lo \& Bullock, 2014).

Results of the program evaluation have shown that as to the question of the extent of CB of students before and after participation in the program, analysis of the data shows that after the program implementation, the number of students who reported they were cyber victims 
decreased, mostly in name-calling, mocking the victim's appearance, and trying to make the cyber victim feel bad about him-/herself. The intervention program discussed and dealt with these issues. However, in some kinds of abuse, such as damaging the victim's reputation, or threats, a small change or no change at all occurred. A decrease, albeit smaller, was also observed in the control group. We can assume that when such a program is assigned to a particular age group in the school, it may have some effect on all students, and not just the experimental group.

On the question of whether a change occurred in the emotional and practical reaction of the cyber victims before and after participating in the program, analysis of the data shows a change in both groups, but in different parameters: The experimental group reported a change in behavior at home and at school after the program, and a decrease in wanting to go to school. They also reported an increase in most emotional reactions, such as worry, tension, frustration, and anger. The control group reported the main increases in the emotional reactions of frustration, tension, and anger. These data may indicate an increase in the awareness of the students in the experimental group of the severity of $\mathrm{CB}$, and an increase in their worrying and frustration as a consequence of abuse and their wish to distance themselves from the perpetrators who abused them (and therefore, apparently, a decrease in their wish to go to school).

On the question of whether a change occurred in the behavior of bystanders who witnessed CB before and after they participated in the intervention program, analysis of the bystanders' data shows a decrease in the general reporting of witnessing bullying acts, but this decrease is less than the decrease in the percentage of reports of CB $(6.2 \%$ vs. $12.4 \%)$. The decrease in the report of witnessing $\mathrm{CB}$ can be explained by the fact that the decrease in the number of cyber victims means fewer bystanders witness CB. However, the decrease in witnessing CB is lower, and therefore we see an increase in awareness and in the number of people who report having witnessed CB. Analysis of the bystanders' reactions seems to show an improvement in their behavior. We see a decrease in abusive behavior by bystanders, such as sharing and "liking" abusive posts, and an increase in ignoring abuse (ignoring abuse is behavior that weakens the perpetrator and decreases the harm to the victim). We also see an increase in the percentage of reporting to teachers.

The results of the study seem to show a decrease in CB acts, some change in victims' emotions, and a change in the behavior of the bystanders; therefore, the intervention program seems to have achieved most of its aims. The results make a case for continued research to extend the variety of $\mathrm{CB}$ behaviors related to the program and to try to implement the program over a longer period of time in order to produce a stronger effect.

Furthermore, to continue to increase the influence of the bystanders' behavior, we make a case for examining the possibility of teaching longer programs, such as ones that continue throughout the entire school year over several years, and examining their contribution to the students, the teaching staff, and the school climate. Further research into variables that have been found to predict school bullying behavior, such as the school atmosphere, social situation, family situation, and so on, would be worthwhile (Brighi et al., 2012). 
Because cyber victimization and witnessing $\mathrm{CB}$ are significantly and positively correlated (82.8\% in the experimental group and $87.5 \%$ in the control group are both victims and bystanders), research for the purpose of understanding this connection and its significance in future assimilation of the program would also be worthwhile.

Analysis of the data shows an improvement in some of the parameters, both in the experimental group and in the control group (although the improvement is smaller in the control group). Two major factors could explain the improvement that was reported in the control group: First, all the educators of the in the class-age group took part in the teachers' course, which may have influenced the behavior of the teachers in the control classes; second, because of the social characteristics of the age group, completely separating the experimental group from the control group was impossible. CB and reactions of bystanders who witness abuse frequently take place throughout the age group, and not only in one class, which may explain the improvement in both groups. A meta-analysis review on intervention programs for coping with bullying and cyberbullying (Kaduri \& Alfasi, 2018) revealed that each development period offers different prevention options, and that approaches and strategies can be identified that are particularly appropriate for primary school students, seventh graders, eighth graders, and $12^{\text {th }}$ graders .However, for eighth graders, no prevention programs had a significant positive effect. The presented intervention program may have an encouraging effect on efforts to reduce $\mathrm{CB}$ in this age group. To validate the results, however, the program should be implemented in more and much larger samples, and should make needed improvements on the basis of the current results.

This program has several additional advantages. For instance, it was spread out over a number of weeks, and classroom educators who were properly prepared and who knew the students personally implemented it. Thus, such a program can continue to exist at the end of the research, because of the knowledge and skills that were provided to the teaching staff. In addition It was expected that the escalation in students' self-efficacy and empathy are expected to increase after involvement in the program and may lead to more effective coping in any forthcoming acts of CB. However, The results show the empathy of the participants who had a low sense of empathy increased and no change in self-efficacy after the program. The increase in empathy is essential because it may lead to a deeper understanding of the victim's situation and to a willingness to help. On the other hand, self-efficacy seems to be more difficult to influence in the relatively short duration of the program, and a longer and more focused program is required in order to bring about a change that can also affect bystanders' willingness to help victims online.

\subsection{Limitations}

The program is a three-month length. It may be asumed that this period of time is not sufficient to produce extensive changes in the behaviors and feelings of the participants as well as changes in their personality traits: empathy and self-efficacy. Thus it might be difficult to make conclusions and generalizations after only three month $\mathrm{f}$ intervention. In that sense we can address it as a piloting, aiming to be expanded in future studies, widening the implementation of the program to once in a week through the whole school year, or at least 
another three or six months. Changing youth cyber-culture is a continuing complex task that definitely need more time. But, since it has shown a direction of a positive impact we suggest to widening the program, than reevaluating. We should also take into consideration that any intervention program is not isolated from other events and acts surrounding the youth regarding $\mathrm{CB}$ that may bias slightly the results, such as: Social media, Education ministry guidance, Police services and more.

In addition, this program referred to two personal characteristics, and it is important to take into consideration more variables that may be related to bystanders behaviors in CB episodes, such as: social support and resilience. In addition, an in- depth examination of the relationship between cyber victimization and bysatnding may lead to a better understanding of these relationships that were exposed in this study. In addition, this program and research accompanying it are preliminary and have so far been conducted in one school, whereas the socio-demographic characteristics of the participants are not significantly different. For better ability of generalization this intervention program should be implemented and examined in the context of socio-economic differences, and age-groups differences (for example younger children with appropriate adaptations). To validate the results, however, the program should be implemented in more and much larger samples. Another limitation is related to the random sampling of the experimental and control groups that may have a potential impact of the uncontrolled individual differences on their reported findings.

However, despite these reservations, the study findings indicate that bystanders to $\mathrm{CB}$ episodes have a significant potential role in influencing prevention and coping with $\mathrm{CB}$ and it is worthwhile to continue and expand a bystander based intervention program for coping with CB.

\subsection{Conclusions}

The greater the use of the internet among adolescents, the greater the risk of exposure to $\mathrm{CB}$, which can lead to damage to the school climate, as well as to social, educational, and emotional harm to the students involved. The importance of bystanders in influencing $\mathrm{CB}$ events is critical because of their large numbers on the internet and in social media networks, and because their response may affect the victim's level of victimization, further harm and the perpetrator's continued behavior (Mason, 2008; Wong-Lo \& Bullock, 2014; Olenik-Shemesh et al. ., 2015). Thus, they may play a key role in reducing and preventing CB acts, identifying the cyber victims, helping them, and strengthening their peer circle of support. Such a program may improve the probability of victims being assisted by bystanders in real time.

\section{References}

Almenayes, L. (2017). The relationship between cyberbullying victimization and depression: The moderating effects of gender and age. Social Networking, 6, 215-223. https://doi.org/10.4236/sn.2017.63014

Ang, R.P. (2015). Adolescent cyberbullying: A review of characteristics, prevention and 
intervention strategies. Aggression and Violent Behavior, 25, 35-42. https://doi.org/10.1016/j.avb.2015.07.011

Ang, R. P., \& Goh, D. H. (2010). Cyberbullying among adolescents: The role of affective and cognitive empathy, and gender. Child psychiatry \& Human Development, 41, 387-397. https://doi.org/10.1007/s10578-010-0176-3

Atkins, M. J. (1993). Theories of learning and multimedia applications: An Overview. Research Paper in Education, 8(2), 251-271.

Bilic, V. (2013). Violence among peers in the real and virtual world. Pediatrics Today, 9(1), 78-90. https://doi.org/10.5457/p2005-114.65

Brighi, A., Melotti, G., Guarini, A., Genta, M.L., Ortega, R., Mora-Merchán, J., Smith, P.K., \& Thompson, F. (2012). Self-esteem and loneliness in relation to cyberbullying in three European countries. In D. Cross, P.K. Smith \& Q. Li (Eds.), Cyberbullying in the Global Playground: Research from International Perspectives. London, Blackwell.

Barak, A. (2006). Youth and internet: Face. Culture, Society and Education, 37, 48-58.

Barlinskw, J., Szuster, A., \& Winiewski, M. (2018). Cyberbullying among adolescent bystanders: Role of affective versus cognitive empathy in increasing prosocial cyberbystander behavior. Frontires in Psychology, 9, 799-812. https://doi.org/10.3389/fpsyg.2018.00799

Bastiaensens S., Vandebosch H., Poels K., Van Cleemput K., De Smet A., \& De Bourdeaudhuij I. (2014). Cyberbullying on social network sites. An experimental study into bystanders' behavioural intentions to help the victim or reinforce the bully. Computer in Human. Behavior, 31, 259-271. https://doi.org/10.1016/j.chb.2013.10.036

Cassidy, W., Brown, K., \& Jackson, M. (2012). 'Under the radar': Educators and cyberbullying in schools. School psychology international, 33(5), 520-532. https://doi.org/10.1177/0143034312445245

Connell, N. M., Schell-Busey, N. M., Pearce, A. N., \& Negro, P. (2014). Badgrlz? Exploring sex differences in cyberbullying behaviors. Youth Violence and Juvenile Justice, 12(3), 209-228. https://doi.org/10.1177/1541204013503889

Cross, D., Lester, L., Barnes, A., Cardoso, P., \& Hadwen, K. (2015). If it's about me, why do it without me? Genuine student engagement in school cyberbullying education. International Journal of Emotional Education, 7(1), 35-51.

DeSmet, A., Aelterman, N., Bastiaensens, S., Van Cleemput, K., Poels, K., Vandebosch, H., Cardon, G., \& De Bourdeaudhuij, I. (2015). Secondary school educators' perceptions and practices in handling cyberbullying among adolescents: A cluster analysis. Computers \& Education, 88, 192-201. https://doi.org/10.1016/j.compedu.2015.05.006

Doane, A. N., Pearson, M. R., \& Kelley, M. L. (2014). Predictors of cyberbullying perpetration among college students: An application of the theory of reasoned action. 
Computers in Human Behavior, 36, 154-162.

Espelage, D. L., Hong, J. S., Kim, D. H., \& Nan, L. (2017). Empathy, attitude towards bullying, theory-of-mind, and non-physical forms of bully perpetration and victimization among us middle school students. In Child \& Youth Care Forum (pp. 1-16). Springer US.

Gázquez, M. (2010). Comparación de tres programas de prevención de drogas en el ámbito escolar [Comparison of three drug prevention programs in schools]. Doctoral Thesis. Miguel Hernández University.

Hen, M. (2010). Sense of self-efficacy and empathy among teachers who integrate students with special needs in the class. Maof and Maase, 13, 134-165.

Kaduri, A., \& Alfasi, Y. (2018). Examining the effectiveness of school intervention programs and school-based prevention program for the prevention of violence, drugs and alcohol (A Report). Ministry of Public Security, Israeli National Authority for Community Security.

Kazerooni, F., Hardman, S., Taylor, N., \& Janis Whitlock, J. (2018). Cyberbullying bystander Intervention: The number of offenders and retweeting predict likelihood of helping a cyberbullying victim. Journal of Computer-Mediated Communication, 23(3), 146-162. https://doi.org/10.1093/jcmc/zmy005.

Kearsley, G., \& Shneiderman, B. (1998). Engagement Theory: A framework for technology-based teaching and learning. Educational Technology, 38, 20-23. https://doi.org/10.1007/BF02299671

Korem, (2016). Developing students' social competence for coping with teasing at school and in the internet. Circles of Education, 6, 204-215.

Latané, B., \& Darley, J. M. (1970). The unresponsive bystander: Why doesn't he help?. Appleton-Century-Crofts, 341-344.

Lize, S. E., Iachini, A. L., Tang, W., Tucker, J., Seay, K. D., Clone, S., DeHart, D., Browne, T. A. (2017). Meta-analysis of the effectiveness of interactive middle school cannabis prevention programs. Prevention Science, 18, 50-60. https://doi.org/10.1007/s11121-016-0723-7

Lee, S., Kim, C. J., \& Kim, D. H. (2015). A meta-analysis of the effect of school-based anti-bullying programs. Journal of Child Health Care, 19, 136-153. https://doi.org/10.1177/1367493513503581

Mason, K. L. (2008). Cyber Bullying: A preliminary assessment for school personnel. Psychology in the Schools, 45(4), 323-348. https://doi.org/10.1002/pits.20301

Mehrabian, A., \& Epstein, N. (1972). A measure of emotional empathy. Journal of personality, 40(4), 525-543. https://doi.org/10.1111/j.1467-6494.1972.tb00078.x

Prensky, M. (2001). Digital natives, digital immigrants. Part 1. On the Horizon, 9(5), 1-6. 
https://doi.org/10.1108/10748120110424816

Olenik-Shemesh, D., \& Heiman, T. (2012). On-line violence and cyberbullying. Hed Hahinuch, 17, 25-35. https://doi.org/10.1080/13632752.2012.704227

Olenik-Shemesh, D., Heiman, T., \& Eden, S. (2015). Bystanders' Behavior in Cyberbullying episodes: active and passive patterns in the context of personal-socio-emotional factors. Journal of interpersonal violence, $32(1), \quad 23-48$. https://doi.org/10.1177/0886260515585531

Semple, A. (2000). Learning theories and their influence on the development and use of educational technology. Australian Science Teaching Journal, 46(3), 21-28.

Sittichai, R. (2014), Information technology behavior cyberbullying in Thailand: Incidence and predictors of victimization and cyber - victimization. Asian Social Science, 10(11), 132-140. https://doi.org/10.5539/ass.v10n11p132

Smith, P. K., Mahdavi, J., Carvalho, M., Fisher, S., Russell, S., \& Tippett, N. (2008). Cyberbullying: It's nature and impact in secondary school pupils. Journal of Child $\begin{array}{llll}\text { Psychology and } \quad \text { Psychiatry, } & \text { 49(4), }\end{array}$ https://doi.org/10.1111/j.1469-7610.2007.01846.x

Snyder, C. R., Shane, J., Lopez, R., Jennifer T., \& Pedrotti, J. (2005). Positive psychology: The scientific and practical explorations of human strengths. Second ed. Los Angeles: SAGE, 2011. (267-275).

Strom, P. S., \& Strom, R. D. (2005). When teens turn cyberbullies. Education Digest, 71(4), $35-41$.

Ttofi, M. M., \& Farrington, F. D. (2011). Effectiveness of school-based programs to reduce bullying: A systematic and meta-analytic review. Journal of Experimental Criminology, 7, 27-56. https://doi.org/10.1007/s11292-010-9109-1

Wong-Lo, M., \& Bullock, L. M. (2014). Digital metamorphosis: Examination of the bystander culture in cyberbullying. Aggression and Violent Behavior, 19, 418-422. https://doi.org/10.1016/j.avb.2014.06.007

Ybarra, M. L., \& Mitchell, K. J. (2004). Online aggressor/targets, aggressors, and targets: a comparison of associated youth characteristics. Journal of Child Psychology and Psychiatry, 45, 130. https://doi.org/10.1111/j.1469-7610.2004.00328.x

Waschbusch, D. A., Breaux, R. P., \& Babinski, D. E. (2018). School-Based Interventions for aggression and defiance in youth: A framework for evidence-based practice. School Mental Health, 11(1), 1-14. https://doi.org/10.1007/s12310-018-9269-0

Wright, M., Wachs, S., \& Harper, B. (2018). The moderation of empathy in the longitudinal association between witnessing cyberbullying, depression, and anxiety. Cyberpsychology, Journal of Psychosocial Research on Cyberspace, 12(4), article 6. https://doi.org/10.5817/CP2018-4-6 


\section{Copyright Disclaimer}

Copyright for this article is retained by the author(s), with first publication rights granted to the journal.

This is an open-access article distributed under the terms and conditions of the Creative Commons Attribution license (http://creativecommons.org/licenses/by/3.0/). 